\title{
Acoustic Emission Behavior of Rock-Like Material Containing Two Flaws in the Process of Deformation Failure
}

\author{
Quan-Sheng Liu, ${ }^{1,2}$ Jie Xu, ${ }^{1}$ Bin Liu, ${ }^{2}$ and Jing-Dong Jiang' \\ ${ }^{1}$ School of Civil Engineering, Wuhan University, Wuhan, Hubei 430072, China \\ ${ }^{2}$ Institute of Rock and Soil Mechanics, Chinese Academy of Sciences, Wuhan, Hubei 430071, China
}

Correspondence should be addressed to Quan-Sheng Liu; liuqs@whrsm.ac.cn

Received 17 October 2014; Revised 14 February 2015; Accepted 17 February 2015

Academic Editor: Shimin Liu

Copyright (C) 2015 Quan-Sheng Liu et al. This is an open access article distributed under the Creative Commons Attribution License, which permits unrestricted use, distribution, and reproduction in any medium, provided the original work is properly cited.

\begin{abstract}
Many sudden disasters (such as rock burst) by mining extraction originate in crack initiation and propagation. Meanwhile a large number of shock waves are produced by rock deformation and failure. With the purpose of investigating crack coalescence and failure mechanism in rock, experimental research of rock-like materials with two preexisting flaws was performed. Moreover, the $\mathrm{AE}$ technique and photographic monitoring were adopted to clarify further the procedure of the crack coalescence and failure. It reveals that $\mathrm{AE}$ location technique can record the moments of crack occurrences and follow the crack growth until final failure. Finally, the influence of different flaw geometries on crack initiation strength is analyzed in detail. This research provides increased understanding of the fracture mechanism of mining-induced disasters.
\end{abstract}

\section{Introduction}

With the development of underground engineering excavating technology, more and more new equipment and new strategies are applied into mining industry. However, the capacity of mining disaster prevention and mitigation cannot meet the productivity demands. Many sudden disasters (such as rock burst) by mining extraction originate in the linkage of preexisting flaws due to the initiation, propagation, and interaction of new cracks and existing fractures. Meanwhile a large number of shock waves are produced by rock deformation and failure. Therefore, it is very urgent and important to understand the mining-induced shock waves during crack initiation, coalescence, and failure of rock material.

Many experimental investigations [1-4] have been carried out on enhancing the understanding of crack coalescence. The experimental results indicated that the mechanical behaviors of rock failure were closely bound up with the geometries of flaws. Meanwhile, the coalescence behavior of cracks is of great importance and difficulty. Following the development of test research, rock-like materials gain more attention and have been widely studied.
Vásárhelyi and Bobet [5], Sagong and Bobet [6], Zhou et al. [7], and Zhu et al. [8] have investigated the crack coalescence behavior by loading rock-like materials with different flaw geometries. Wong and Einstein [9] carried out an experimental study on cracking and coalescence behavior with molded gypsum and marble samples, which showed that the cracking processes and macroscopic deformation were bound up with the underlying microscopic change. Based on the combination of numerical simulations and experiments, Haeri et al. [10] have investigated the crack coalescence mechanism and propagation paths according to Mode I and Mode II stress intensity factors. In order to research the effect of flaw angle and distribution density on the failure characteristics, Pu and Cao [11] have performed experimental study on rock-like samples with prefabricated closed multiflaws. In accordance with cracking behaviors in modeled gypsum and Carrara marble samples, Wong and Einstein [12] have obtained seven different crack types. The reason for choosing rock-like materials is threefold: first, a large number of samples can be easily prepared; second, a wide range of brittle rocks can be represented; third, many 


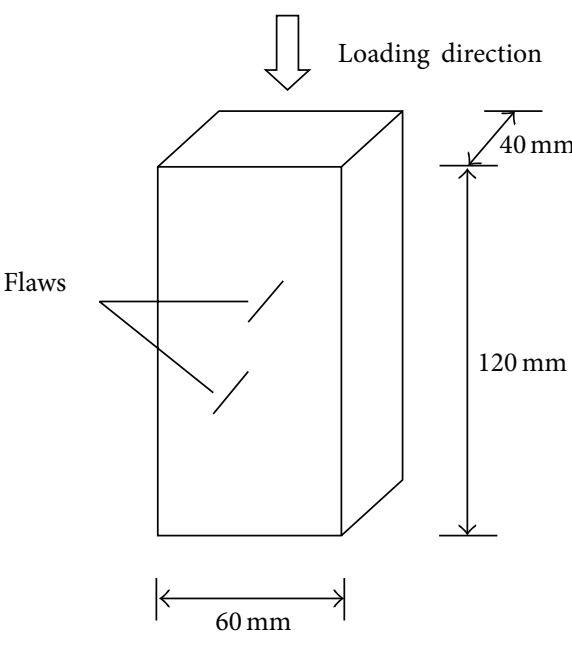

(a)

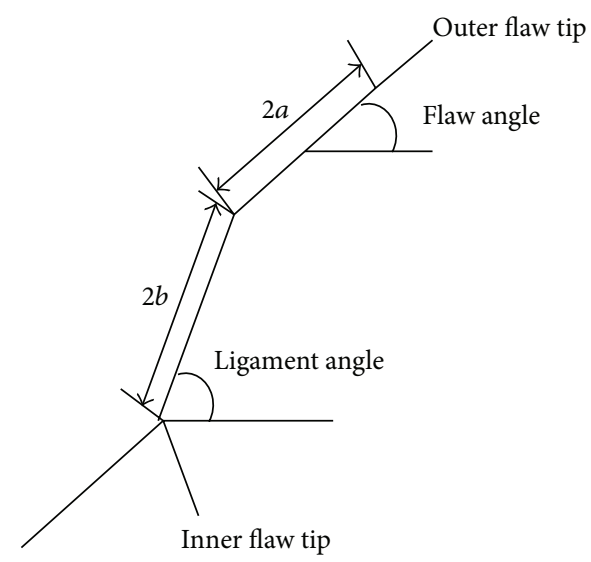

(b)

Figure 1: Sample with two flaws. (a) Overall view and (b) geometry of the flaws.

of previous experimental results can be compared with the current investigation.

Acoustic emission technique (AE) has the capability to efficiently reflect the initiation and coalescence of cracks by tracing the mining-induced shock waves, which has been widely applied to many studies $[13,14]$ of crack behavior in the rock material. With the purpose of better understanding frost weathering mechanisms of rocks, Duca et al. [15] conducted an experimental study on the stored elastic energy by $\mathrm{AE}$ technique, which was released accompanied by the growth of microcracks during freezing tests. A series of AE location tests were carried out by Ting et al. [16] under unloading conditions, which indicated that energy increasing rate and $\mathrm{AE}$ space-time evolvement rules during strength failure process were dependent on the unloading rates. Jouniaux et al. [17] studied the fracturing and slip behaviors of the samples containing a preexisting macroscopic healed joint, which showed that precursory localization of microfractures in the final rupture plane had been observed in the early stage of deformation by AE technique. Based on the analysis of AE parameters in microcracking activity, Vidya Sagar et al. [18] found the AE behavior characteristics of each stage were linked closely with the number and distribution of microcracks. In order to identify the characteristics of crack coalescence behaviors in sandstone samples, Yang et al. [1921] adopted the $\mathrm{AE}$ technique to record the real-time crack coalescence process of the samples in the whole loading course. All studies show that AE has the capacity to efficiently highlight the moments of crack occurrences and follow the crack growth until final failure.

With the purpose of figuring out the strength failure mechanism and crack coalescence behavior in rock materials, $\mathrm{AE}$ technique and photographic monitoring were used in the uniaxial compression tests for samples containing two parallel flaws. Moreover, the whole process of the real-time crack coalescence was also recorded by tracing mininginduced shock waves in the whole loading course, which was not carried out in rock-like materials previously. In this paper, the researching emphasis centralizes in investigating the effect of the geometry (flaw angle and ligament angle) on the strength failure mechanism of rock-like materials and in studying real-time crack coalescence process under uniaxial compression on the foundation of photographic monitoring and $\mathrm{AE}$ technique combination.

\section{Sample Materials and Experimental Techniques}

2.1. Sample Preparation. The samples were made of highstrength gypsum and water-cement ratio is 1 . The size and flaw geometry of the samples are shown in Figure 1. Each sample was cast in a mold with internal dimensions of $60 \mathrm{~mm} \times 40 \mathrm{~mm} \times 120 \mathrm{~mm}$. Meanwhile, the open flaws were produced with different-sized metallic shims, which are $0.2 \mathrm{~mm}$ in thickness, $60 \mathrm{~mm}$ in length, and $10-30 \mathrm{~mm}$ in width. In order to further investigate the influence of flaw geometry on the crack coalescence behavior, different geometries of two parallel flaws were chosen, which were set by varying inclination angle $(\alpha$ and $\beta$ ) while keeping two constants $(2 a=14 \mathrm{~mm}$ and $2 b=16 \mathrm{~mm})$. Two flaw inclination angles were used: $45^{\circ}$ and $75^{\circ}$; six ligament angles were used: $45^{\circ}, 60^{\circ}, 75^{\circ}, 90^{\circ}, 105^{\circ}$, and $120^{\circ}$.

To obtain the physicomechanical parameters of the rocklike materials, uniaxial and biaxial compression tests were done with the standard cylindrical samples of $50 \mathrm{~mm}$ in diameter and $100 \mathrm{~mm}$ in length and Brazilian splitting tests were done with the samples of $50 \mathrm{~mm}$ in diameter and $50 \mathrm{~mm}$ in length. The physicomechanical parameters of intact samples are shown in Table 1.

2.2. Test Equipment. A servo-controlled hydraulic testing machine, namely, RMT-150C (Figure 2(a)), was used in the experiment, which can perform well in load or displacement control. The maximum capacity of RMT-150C was $1 \mathrm{MN}$ and 
TABLE 1: The physicomechanical parameters of intact samples.

\begin{tabular}{lccccccc}
\hline$\sigma_{c}(\mathrm{MPa})$ & $\sigma_{t}(\mathrm{MPa})$ & $E(\mathrm{GPa})$ & $c$ & $\varphi\left(^{\circ}\right)$ & $\rho\left(\mathrm{g} / \mathrm{cm}^{3}\right)$ & P-wave velocity $(\mathrm{m} / \mathrm{s})$ & S-wave velocity $(\mathrm{m} / \mathrm{s})$ \\
\hline 5.45 & 0.90 & 1.30 & 2.44 & 9.03 & 0.84 & 3123 & 2657 \\
\hline
\end{tabular}

Note: $\sigma_{c}=$ uniaxial compressive strength, $\sigma_{t}=$ tensile strength, $\varphi=$ internal friction angle, $c=$ cohesive force, and $\rho=$ density.

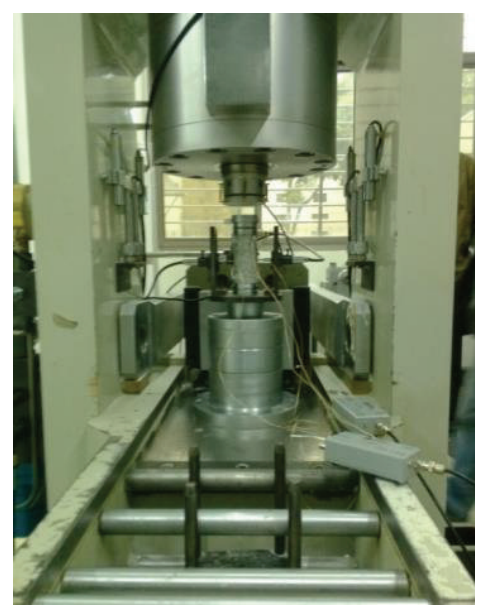

(a) RMT-150C

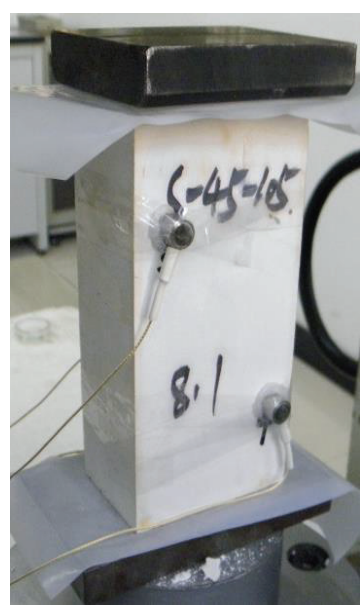

(b) Experimental setup for the sample

FIGURE 2: RMT-150C testing system and experimental setup of samples.

all the real-time data were recorded and analyzed in time. The samples were loaded in the displacement-controlled condition and the stain rate was set as $1 \times 10^{-3} \mathrm{~mm} / \mathrm{s}$. In addition, two rigid steel blocks were placed between the testing samples and loading frame. With the purpose of decreasing the influence of the friction effects and obtaining more accurate testing results, plastic cushions were placed between the end face of samples and rigid steel blocks, as shown in Figure 2(b).

A multichannel, high-speed AE testing system, namely, PCI-2, was used to acquire the real-time AE information, which was manufactured by American Physical Acoustic Corporation (Figure 3(a)). The AE system has become mature as a technique for monitoring the crack growth in rock materials, which is composed of $\mathrm{AE}$ transducers, preamplifier, signal acquisition, and so on. In this study, $\mathrm{AE}$ signals were amplified by $40 \mathrm{~dB}$, and the amplitude threshold, the sampling frequency, and the sampling length were set at $18 \mathrm{mV}, 2.5 \mathrm{MHz}$, and 8192, respectively. Eight Nano-30 type sensors are used to acquire $\mathrm{AE}$ signals, of which the operating frequency is $100-400 \mathrm{kHz}$. Each sensor was equipped with a 1220A-AST type preamplifier. The sensors were fixed on rock faces by plastic tapes and Vaseline was used for coupling, as shown in Figure 3(b). Before the test, a pencil lead break (PLB) was conducted to check out coupling quality of the acoustic emission sensor with the specimen and correct the AE location system, shown in Figure 3(b). If the amplitude value tested by one $\mathrm{AE}$ sensor was above $95 \mathrm{~dB}$, the sensor could be considered to have a good coupling quality with the specimen. If the location of the AE event tested by AE setup was close to the actual location, this system could achieve the demand of position control. Otherwise the PLB tests should be repeated and setup parameters should be modified until the location has met the requirements. Besides, the velocity of longitudinal wave and transverse wave is $3123 \mathrm{~m} / \mathrm{s}$ and $2657 \mathrm{~m} / \mathrm{s}$, respectively.

\section{Strength and Deformation Behavior}

Take flaw angles $\alpha=45^{\circ}$ and $\alpha=75^{\circ}$, for example; the uniaxial compression curves for the samples containing two flaws are shown in Figure 4. It can be found that flaw angle $\alpha$ and ligament angle $\beta$ make a great difference in the strength and deformation properties of rock-like materials, and the detailed influence will be analyzed in the following.

3.1. Relationship between Stress and Strain for the Samples with Different Flaw Geometries. The relationship between stress and strain for the samples containing two parallel flaws can go through approximately four classic stages, that is, flaw closure, elastic deformation, crack initiation and propagation, and strain-softening.

At the initial stage of the stress-strain curves, the downward concave and nonlinear characteristics are clearly observed, which result from the closure of some primary pores and voids at low stress levels and are defined as flaw closure. Moreover the better consistency of the rigidity for all samples at this stage lies in the better homogeneity of tested materials. With the increase of stress, the relationship of stress and strain is at the stage where the linear stressstrain behavior of flawed samples keeps unchanged although there are some irrecoverable processes, which is defined as elastic deformation. Moreover, the slope of the line at elastic deformation stage is dependent distinctly on ligament angle 


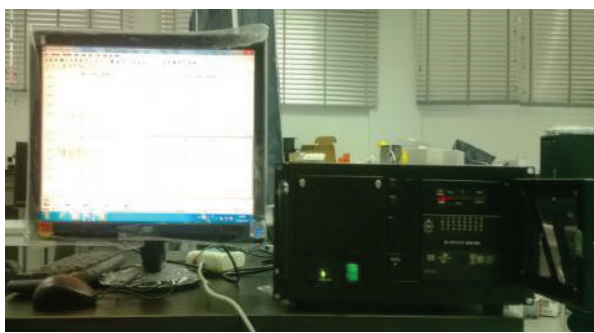

(a) AE PCI-2

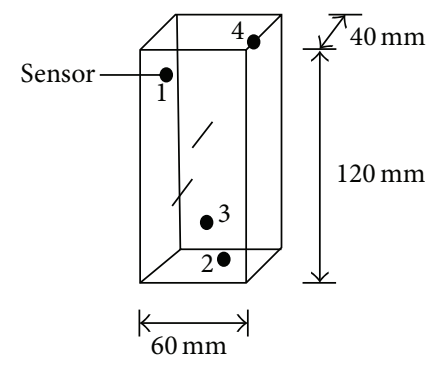

(b) Setup for sensors

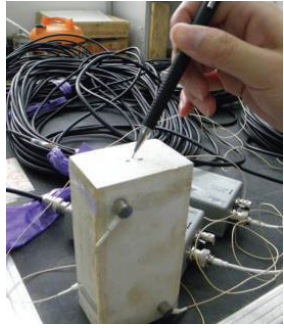

(c) PLB

FIgURE 3: AE PCI-2 acoustic emission system.

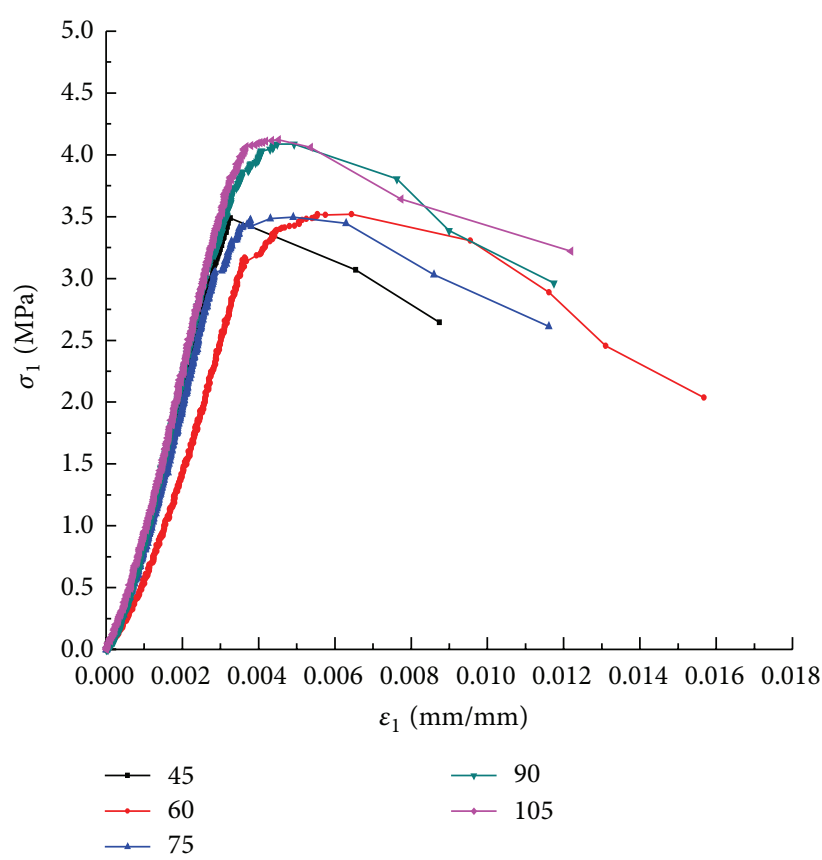

(a) $\alpha=45^{\circ}$

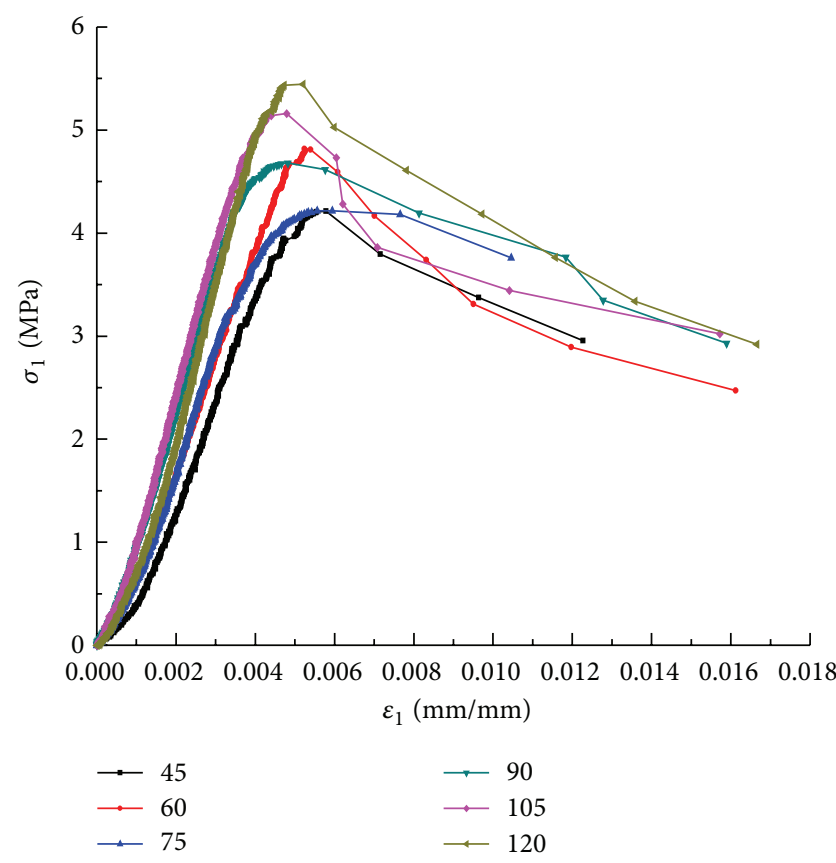

(b) $\alpha=75^{\circ}$

Figure 4: Axial stress-strain curves of the samples, in which (a) and (b), respectively, show the flaw angles $\alpha=45^{\circ}$ and $\alpha=75^{\circ}\left(\sigma_{1}=\right.$ axial stress and $\varepsilon_{1}=$ axial strain) (black, red, blue, dark cyan, magenta, and dark yellow correspond to $45^{\circ}, 60^{\circ}, 75^{\circ}, 90^{\circ}, 105^{\circ}$, and $120^{\circ}$ of ligament angle $\beta$, resp.).

$\beta$. In accordance with Figure 4 , it is clear that the slope of the line increases with the increase of ligament angle $\beta$. Nevertheless, at the stage of crack initiation and propagation, new cracks will initiate and propagate from the tips of the preexisting flaws, which result from stress concentration. Therefore the stress-strain curve shows distinctly nonlinear deformation before peak strength point. From Figure 4, it is clear that the peak strength of samples with ligament angle $\beta$ $=105^{\circ}$ or $120^{\circ}$ is obviously greater than that of others, so one can conclude that it is more difficult to fail for overlapping flaw geometries $\left(\beta \geqslant 90^{\circ}\right)$ than nonoverlapping ones $(\beta \leqslant$ $\left.90^{\circ}\right)$. When the relationship of stress and strain develops into the strain-softening stage, the macroscopic crack occurs and then the postpeak behavior shows a slower fall.

\subsection{Effect of Different Flaw Geometries on Mechanical Param-} eters of Samples. In order to investigate the influence of different flaw geometries on the strength and deformation behaviors, the mechanical parameters of the samples under uniaxial compression are discussed in detail, which are shown in Figure 5.

The uniaxial compressive strength of intact sample is $5.450 \mathrm{MPa}$. Corresponding to the uniaxial strength of the integrity sample, for the samples with $\alpha=45^{\circ}$ or $\alpha=75^{\circ}$, the average reduction extent of uniaxial compressive strength is $32.02 \%$ or $12.76 \%$, respectively. According to Figure 5(a), the uniaxial compressive strength of the samples containing flaw angle $\alpha=75^{\circ}$ is greater than that of samples containing flaw angle $\alpha=45^{\circ}$; therefore, one can conclude that the samples with flaw angle $\alpha=75^{\circ}$ have the ability to bear greater pressure. Moreover, when the $\beta$ angle is increased from 45 to 75 degrees and from 45 to 90 degrees for $\alpha$ angles of 75 and 45 degrees, respectively, the uniaxial compressive strength keeps almost unchanged. Then it begins to increase with increasing 


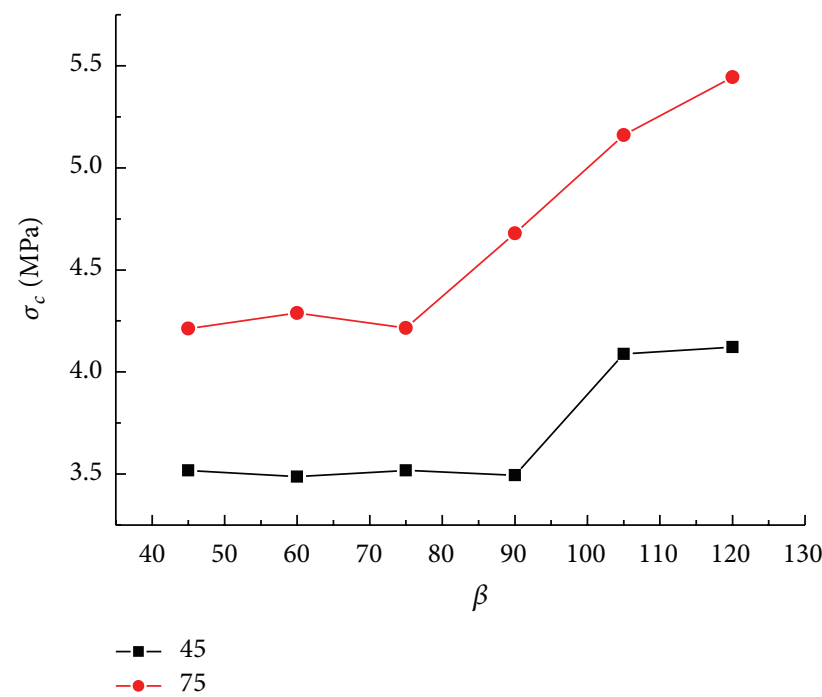

(a) Uniaxial compressive strength

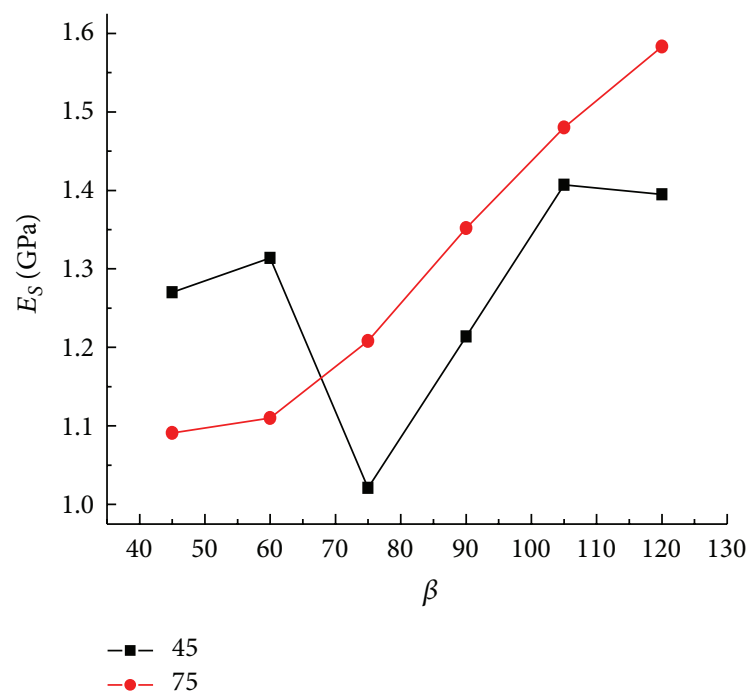

(b) Elastic modulus

FIGURE 5: Effect of flaw angle and ligament angle on mechanical parameters of samples.

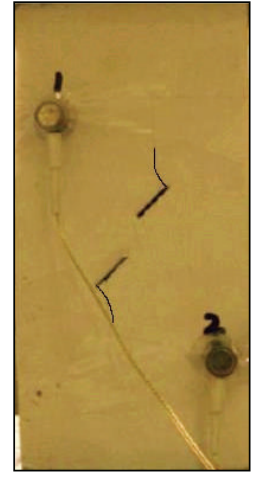

$\sigma_{1}=2.25 \mathrm{MPa}$

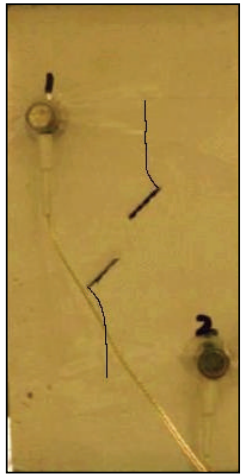

$\sigma_{1}=2.25 \sim 3.152 \mathrm{MPa}$

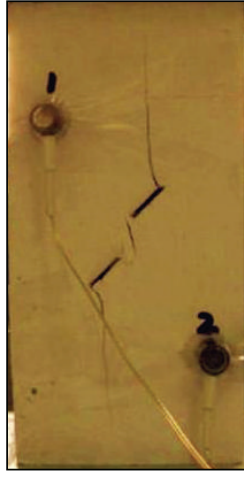

$\sigma_{1}=3.152 \mathrm{MPa}$

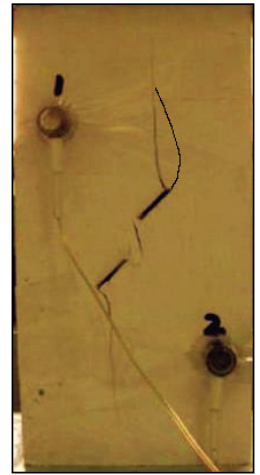

$\sigma_{1}=3.178 \mathrm{MPa}$

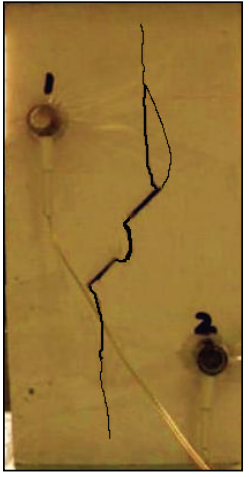

$\sigma_{1}=3.357 \mathrm{MPa}$

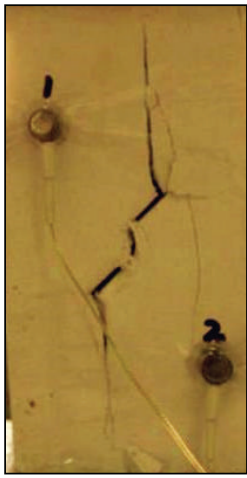

$\sigma_{1}=3.518 \mathrm{MPa}$

FIGURE 6: Real-time recording of crack coalescence process for flawed sample $\left(\alpha=45^{\circ}\right.$ and $\left.\beta=75^{\circ}\right)$.

of ligament angle and the demarcation point is $\beta=90^{\circ}$ for $\alpha$ $=45^{\circ}$ and $\beta=75^{\circ}$ for $\alpha=75^{\circ}$.

In accordance with Figure 5(b), the change rule of the elastic modulus is different from that of uniaxial compressive strength shown in Figure 5(a). For the samples with $\alpha=$ $45^{\circ}$, there is a distinct valley when $\beta=75^{\circ}$; then the elastic modulus increases with the increasing ligament angle. However, the elastic modulus of the samples with $\alpha=75^{\circ}$ keeps an increasing trend from beginning to end, which has a demarcation point at $\beta=60^{\circ}$ because of the different slope of increase.

From the above analysis, one can conclude that the mechanical parameters of the samples with $\alpha=75^{\circ}$ are greater than those with $\alpha=45^{\circ}$, which shows that the flaw angle makes a significant difference on the strength and deformation behaviors. In addition, when $\beta \geqslant 90^{\circ}$, all mechanical parameters increase with increasing ligament angle, which shows that the overlapping flaw geometries have contributed more to the stability of the samples.

\section{Real-Time Recording and Analysis of Crack Coalescence Process for Flawed Samples}

Besides AE energy technique, the AE location-based technology and photographic monitoring were also adopted to illuminate further the characteristics of crack coalescence behaviors in flawed samples under uniaxial compression. It is generally known that the located $\mathrm{AE}$ events directly reflect the time-space distribution of the catastrophic fracture within the samples. Based on the combined results, the real-time recording and analysis of crack coalescence process for flawed samples are shown in detail as in Figure 6.

In accordance with Figures 6, 7, and 8, the crack coalescence process of the sample containing two preexisting flaws $\left(\alpha=45^{\circ}\right.$ and $\left.\beta=75^{\circ}\right)$ in real time was analyzed in detail. Before point $\mathrm{A}\left(\sigma_{1}=2.25 \mathrm{MPa}=64 \% \sigma_{c}\right)$ as shown in Figures 7 and 8 , the stress concentration is too small to reach the material strength, so that there is no crack initiation at the tips of flaws. For the moment, the average modulus is $1.09 \mathrm{GPa}$. 


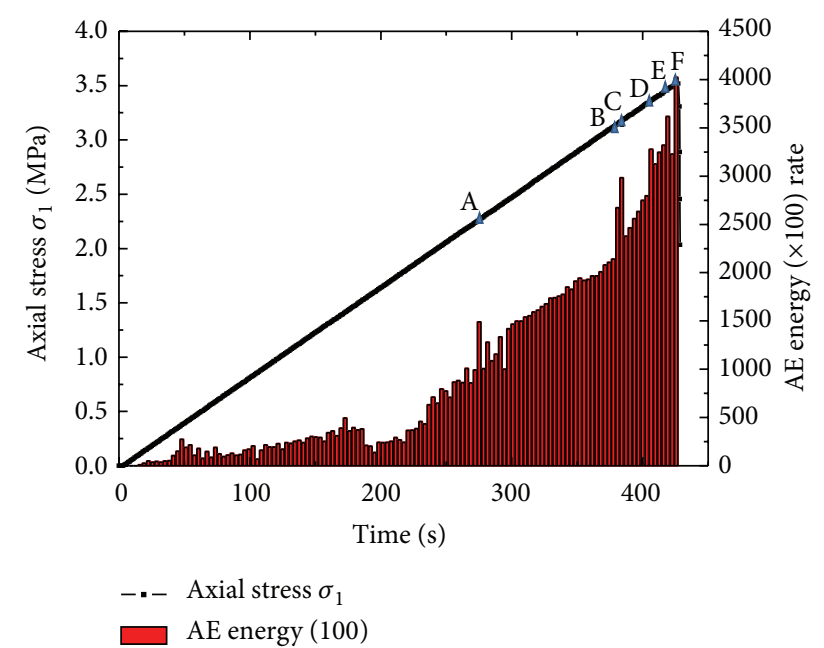

FIgURE 7: Relation between AE energy rate and time of flawed sample $\left(\alpha=45^{\circ}\right.$ and $\left.\beta=75^{\circ}\right)$.

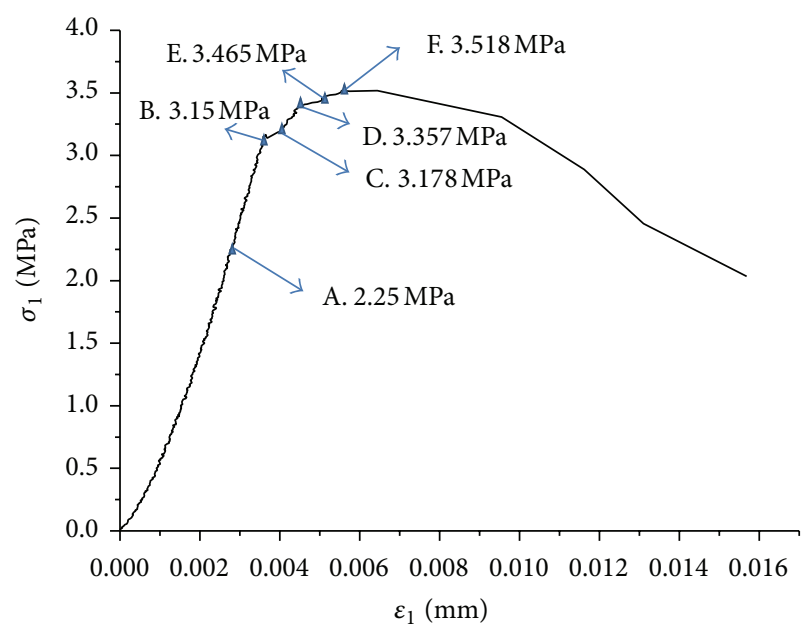

FIGURE 8: Several important points in stress-strain curve for flawed sample $\left(\alpha=45^{\circ}\right.$ and $\left.\beta=75^{\circ}\right)$.

But a wing crack begins to initiate from the outer tips of the preexisting flaws as soon as the sample is loaded to point $\mathrm{A}$, which is identified by AE energy shown in Figure 7. With the axial stress increasing, the wing crack further lengthens and continues to expand along the direction of loading. Due to some minor damage of structural supports inside the material, the average modulus $(1.0 \mathrm{GPa})$ becomes a little lower than the elastic modulus $1.09 \mathrm{GPa}$. When the sample is loaded to the first yielding point $\mathrm{B}\left(\sigma_{1}=3.152 \mathrm{MPa}=\right.$ $\left.89.6 \% \sigma_{c}\right)$, a vertical tensile crack occurs rapidly in the bridge in one second, which can be observed from the AE energy shown in Figure 7. At this time, the axial stress undergoes a minor drop to $3.074 \mathrm{MPa}$ from $3.152 \mathrm{MPa}$. However it is more and more difficult for the wing crack to continue propagating because of the limitation of sample boundary. As time grows, the axial supporting capacity of the sample becomes increasingly great. At the moment of axial stress loaded to point $\mathrm{C}\left(\sigma_{1}=3.178 \mathrm{MPa}=90.3 \% \sigma_{c}\right)$, the second wing crack initiates from the outer tip of the upper flaw. What is more, the average modulus $(\sim 0.262 \mathrm{GPa})$ becomes significantly lower than previous elastic modulus, which results from the serious damage of structural supports inside the materials. When the sample was loaded to the second yielding point $\mathrm{D}\left(\sigma_{1}=3.357 \mathrm{MPa}=95.4 \% \sigma_{c}\right)$, two shear cracks emanate concurrently from the internal tips of two flaws, which indicates that the coalescence occurs. This moment is captured by the AE technology, as shown in Figure 7. During this loading process, it is much in evidence that the axial supporting capacity turns into growing slowly compared to previous period. In addition, the critical decline of average modulus $(\sim 0.096 \mathrm{GPa})$ is largely due to serious damage of structural supports inside the materials. Afterwards, with the sample being loaded to $3.465 \mathrm{MPa}\left(98.5 \% \sigma_{c}\right)$, surface spalling starts to appear on the surface of the sample, which can be obviously observed from Figure 6 . When the sample is loaded to $3.518 \mathrm{MPa}\left(100 \% \sigma_{c}\right)$, at this moment, the first wing crack develops rapidly to the edge of the sample in one second, which leads to the strength failure. At the same time, the axial supporting capacity reduces to $2.035 \mathrm{MPa}$.

The crack coalescence process of flawed sample in real time can be confirmed and characterized by virtue of $\mathrm{AE}$ location technique as well, as shown in Figure 9. At the beginning of load, the $\mathrm{AE}$ events are so little that no rules can be obtained. When the sample is loaded to $2.25 \mathrm{MPa}$ (point A), more AE events are observed at the outer tips of preexisting flaws, indicating that wing crack occurs. At the moment, the number of AE events only accounts for $6.9 \%$ of the total. Afterwards, with the increasing axial stress, a red zone can be distinctly observed in the bridge, which indicates the vertical tensile crack occurs. However the continuous increasing stress leads the $\mathrm{AE}$ events to increase rapidly. At this moment of about $406 \mathrm{~s}$ (corresponding axial stress is $3.357 \mathrm{MPa}$ ), the coalescence occurs, which is shown in Figure 9(e). Meanwhile, the proportion of AE events has risen to $79.3 \%$. When the sample is loaded to $3.518 \mathrm{MPa}$ (corresponding time is $425 \mathrm{~s}$ ), a vertical red zone can be observed through the whole sample, which results from the failure of the sample (Figure $9(\mathrm{~g})$ ).

By adopting the combination of photographic monitoring and AE technique, the crack coalescence behavior and failure process of all other samples with different flaw geometries were also recorded in real time. One can conclude that each bigger elastic modulus decline in all the compression curves signifies a bigger crack initiation, which is also accompanied by greater amplifying AE energy and more $\mathrm{AE}$ location events. Figure 10 summarizes the stress of first crack initiation, which also is called crack initiation strength.

According to Figure 10, we can draw the conclusion that the crack initiation strength is linked closely with flaw angle and ligament angle. To explain in concrete terms, the crack initiation strength in the sample with $\alpha=75^{\circ}$ is higher than that with $\alpha=45^{\circ}$ for each ligament angle except $\beta=45^{\circ}$; that is, the initiation of first crack in the sample with $\alpha=$ $45^{\circ}$ is easier than that with $\alpha=75^{\circ}$. In addition, for the sample with $\alpha=45^{\circ}$, the crack initiation strength showed a trend of fluctuations when the ligament angle was lower than $90^{\circ}$. When the ligament angle increased from $45^{\circ}$ to $60^{\circ}$, 


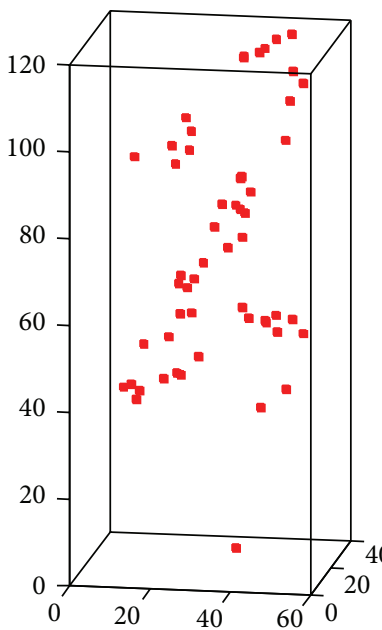

(a) $\sigma_{1}=1.69 \mathrm{MPa}(T=207 \mathrm{~s})$

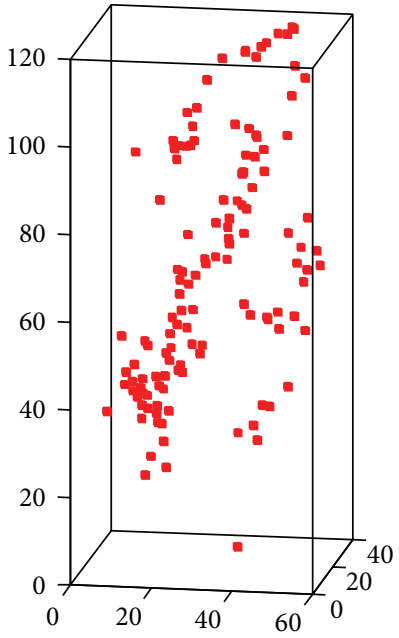

(b) $\sigma_{1}=2.25 \mathrm{MPa}(T=274 \mathrm{~s})$

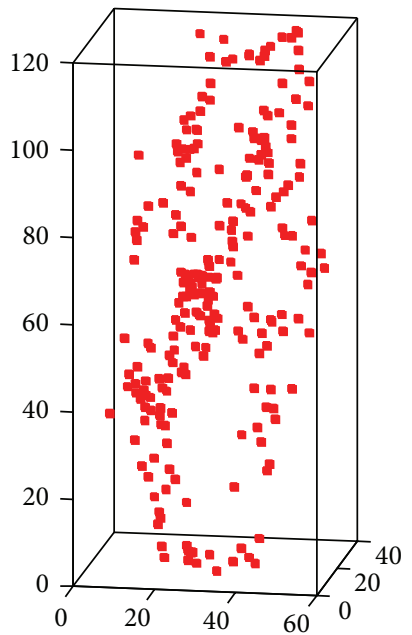

(c) $\sigma_{1}=3.15 \mathrm{MPa}(T=381 \mathrm{~s})$

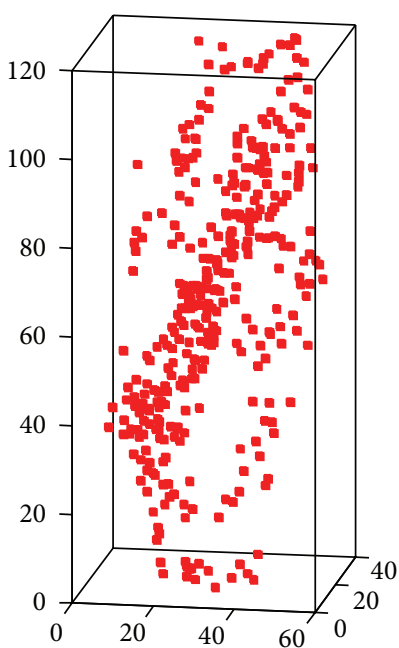

(d) $\sigma_{1}=3.178 \mathrm{MPa}(T=385 \mathrm{~s})$

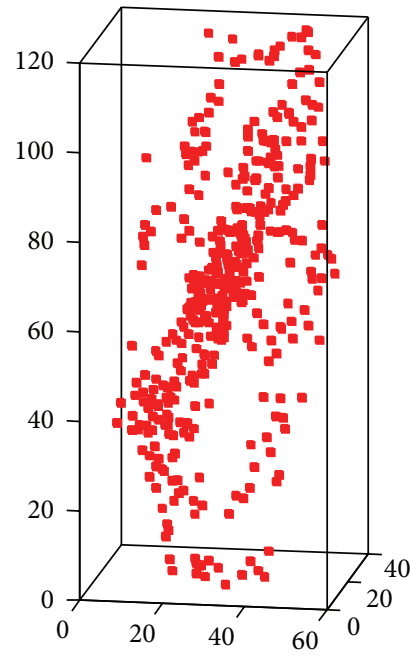

(e) $\sigma_{1}=3.357 \mathrm{MPa}(T=406 \mathrm{~s})$

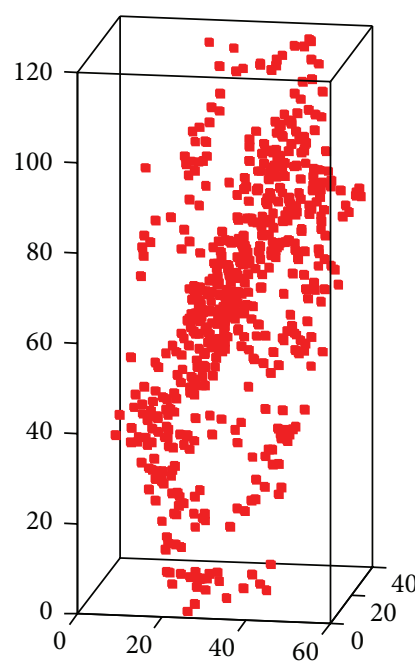

(f) $\sigma_{1}=3.465 \mathrm{MPa}(T=419 \mathrm{~s})$

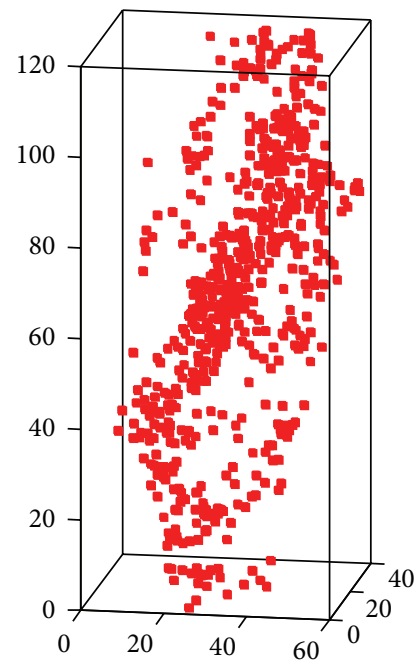

(g) $\sigma_{1}=3.518 \mathrm{MPa}(T=425 \mathrm{~s})$

FIgURE 9: The AE location for cracks initiating and propagating in flawed sample $\left(\alpha=45^{\circ}\right.$ and $\left.\beta=75^{\circ}\right)$.

the crack initiation strength increased from $3.1 \mathrm{MPa}$ to $3.25 \mathrm{MPa}$. Then it decreased to $3.17 \mathrm{MPa}$ at $\beta=75^{\circ}$ and $3.12 \mathrm{MPa}$ at $\beta=90^{\circ}$. After that the crack initiation strength increased with the increase of ligament angle. Similarly, for the sample with $\alpha=75^{\circ}$, the crack initiation strength was $4.52 \mathrm{MPa}$ at $\beta=60^{\circ}$. Then it decreased to $3.8 \mathrm{MPa}$ at $\beta=75^{\circ}$. After that it increased to the maximum value of $5.15 \mathrm{MPa}$ at $\beta=120^{\circ}$. What is more, we can come to a conclusion that the first crack in the sample with smaller ligament angle is easier to initiate than that with larger ligament angle on the whole. Particularly for the sample with overlapping flaw geometries $\left(\beta \geqslant 90^{\circ}\right)$, the crack initiation strength is distinctly higher than that of nonoverlapping flaw geometries $\left(\beta \leqslant 90^{\circ}\right)$.

\section{Conclusions}

This study focused on the influence of the geometry (flaw angle and ligament angle) on the strength failure mechanism of rock-like materials and analyzed real-time crack coalescence process by tracing mining-induced shock waves on basis of $\mathrm{AE}$ technique. It provides better understanding of the fracture mechanism of mining-induced disasters. The main conclusions of this study are the following.

(1) Compared with intact sample, the flawed samples fail with lower strengths, which is closely related to the flaw angle $\alpha$ and ligament $\beta$. The mechanical parameters of the samples with $\alpha=75^{\circ}$ are greater than those with $\alpha=45^{\circ}$. When $\beta \geqslant 90^{\circ}$, all mechanical parameters increase with increasing ligament angle, which shows that the overlapping flaw geometries have contributed more to the stability of the samples.

(2) The crack coalescence behavior and strength failure process of the samples with different flaw geometries are recorded in real time by tracing induced shock waves. Each bigger elastic modulus decline in all the compression curves signifies a bigger crack initiation, 


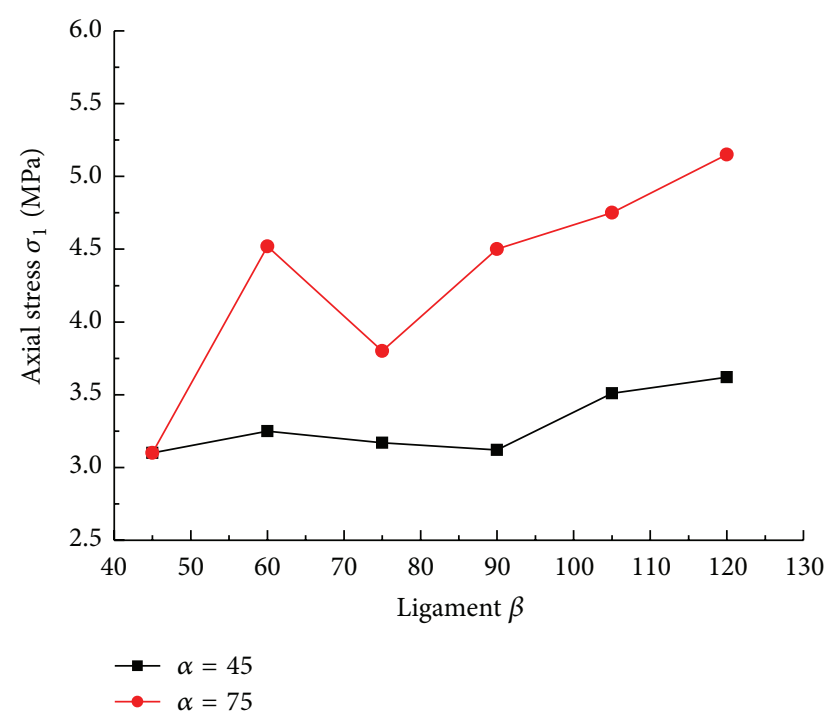

FIGURE 10: Crack initiation strength of the samples with different geometries.

which is also accompanied by greater amplifying $\mathrm{AE}$ energy and more AE location events.

(3) The crack initiation strength is linked closely with flaw angle and ligament angle. The crack initiation strength in the sample with $\alpha=75^{\circ}$ is higher than that with $\alpha=45^{\circ}$ for each ligament angle except $\beta=45^{\circ}$; that is, the initiation of first crack in the sample with $\alpha=45^{\circ}$ is easier than that with $\alpha=75^{\circ}$. Moreover, the initiation of first crack in the sample with smaller ligament angle is easier than that with larger ligament angle on the whole. Particularly for the sample with overlapping flaw geometries $\left(\beta \geqslant 90^{\circ}\right)$, the crack initiation strength is distinctly higher than that of nonoverlapping flaw geometries $\left(\beta \leqslant 90^{\circ}\right)$.

\section{Conflict of Interests}

The authors declare that there is no conflict of interests regarding the publication of this paper.

\section{Acknowledgments}

Financial supports from the National Basic Research Program of China (973 Program) Grant no. 2014CB046904 and the National Natural Science Foundation of China Grant nos. 41130742 and 51474205 are gratefully acknowledged.

\section{References}

[1] G. Chen, J. Kemeny, and S. S. Harpalani, "Fracture propagation and coalescence in marble plates with pre-cut notches under compression," International Journal of Rock Mechanics and Mining Sciences, vol. 30, p. 279, 1993.

[2] H. Jiefan, C. Ganglin, Z. Yonghong, and W. Ren, "An experimental study of the strain field development prior to failure of a marble plate under compression," Tectonophysics, vol. 175, no. 1-3, pp. 269-284, 1990.

[3] L. N. Y. Wong and H. Einstein, "Fracturing behavior of prismatic specimens containing single flaws," in Proceedings of the 41st US Rock Mechanics Symposium (Golden Rocks '06), Omni Press, Golden, Colo, USA, June 2006.

[4] L. G. Zhao, J. Tong, and M. C. Hardy, "Prediction of crack growth in a nickel-based superalloy under fatigue-oxidation conditions," Engineering Fracture Mechanics, vol. 77, no. 6, pp. 925-938, 2010.

[5] B. Vásárhelyi and A. Bobet, "Modeling of crack initiation, propagation and coalescence in uniaxial compression," Rock Mechanics and Rock Engineering, vol. 33, no. 2, pp. 119-139, 2000.

[6] M. Sagong and A. Bobet, "Coalescence of multiple flaws in a rock-model material in uniaxial compression," International Journal of Rock Mechanics and Mining Sciences, vol. 39, no. 2, pp. 229-241, 2002.

[7] X. P. Zhou, H. Cheng, and Y. F. Feng, "An experimental study of crack coalescence behaviour in rock-like materials containing multiple flaws under uniaxial compression," Rock Mechanics and Rock Engineering, vol. 47, no. 6, pp. 1961-1986, 2013.

[8] W. S. Zhu, W. Z. Chen, and J. Shen, "Simulation experiment and fracture mechanism study on propagation of Echelon pattern cracks," Acta Mechanica Solida Sinica, vol. 19, pp. 355-360, 1998.

[9] L. N. Y. Wong and H. H. Einstein, "Crack coalescence in molded gypsum and Carrara marble. Part 1. Macroscopic observations and interpretation," Rock Mechanics and Rock Engineering, vol. 42, no. 3, pp. 475-511, 2009.

[10] H. Haeri, K. Shahriar, M. F. Marji, and P. Moarefvand, "Cracks coalescence mechanism and cracks propagation paths in rocklike specimens containing pre-existing random cracks under compression," Journal of Central South University, vol. 21, no. 6, pp. 2404-2414, 2014.

[11] C.-Z. Pu and P. Cao, "Failure characteristics and its influencing factors of rock-like material with multi-fissures under uniaxial compression," Transactions of Nonferrous Metals Society of China, vol. 22, no. 1, pp. 185-191, 2012.

[12] L. N. Y. Wong and H. H. Einstein, "Systematic evaluation of cracking behavior in specimens containing single flaws under uniaxial compression," International Journal of Rock Mechanics and Mining Sciences, vol. 46, no. 2, pp. 239-249, 2009.

[13] A. Zang, F. C. Wagner, S. Stanchits, G. Dresen, R. Andresen, and M. A. Haidekker, "Source analysis of acoustic emissions in Aue granite cores under symmetric and asymmetric compressive loads," Geophysical Journal International, vol. 135, no. 3, pp. 11131130, 1998.

[14] X. Lei, K. Kusunose, M. V. M. S. Rao, O. Nishizawa, and T. Satoh, "Quasi-static fault growth and cracking in homogeneous brittle rock under triaxial compression using acoustic emission monitoring," Journal of Geophysical Research B: Solid Earth, vol. 105 , no. 3, pp. 6127-6139, 2000.

[15] S. Duca, C. Occhiena, and L. Sambuelli, "A procedure to determine the optimal sensor positions for locating AE sources in rock samples," Rock Mechanics and Rock Engineering, vol. 48, no. 2, pp. 481-493, 2014.

[16] A. Ting, Z. Ru, L. Jianfeng, and R. Li, "Space-time evolution rules of acoustic emission location of unloaded coal sample at different loading rates," International Journal of Mining Science and Technology, vol. 22, no. 6, pp. 847-854, 2012.

[17] L. Jouniaux, K. Masuda, X. Lei et al., "Comparison of the microfracture localization in granite between fracturation and 
slip of a preexisting macroscopic healed joint by acoustic emission measurements," Journal of Geophysical Research B: Solid Earth, vol. 106, no. 5, pp. 8687-8698, 2001.

[18] R. Vidya Sagar, R. V. Prasad, B. K. Raghu Prasad, and M. V. M. S. Rao, "Microcracking and fracture process in cement mortar and concrete: a comparative study using acoustic emission technique," Experimental Mechanics, vol. 53, no. 7, pp. 1161-1175, 2013.

[19] S. Q. Yang and H. W. Jing, "Strength failure and crack coalescence behavior of brittle sandstone samples containing a single fissure under uniaxial compression," International Journal of Fracture, vol. 168, no. 2, pp. 227-250, 2011.

[20] S. Q. Yang, Y. H. Dai, L. J. Han, and Z. Q. Jin, “Experimental study on mechanical behavior of brittle marble samples containing different flaws under uniaxial compression," Engineering Fracture Mechanics, vol. 76, no. 12, pp. 1833-1845, 2009.

[21] S.-Q. Yang, "Crack coalescence behavior of brittle sandstone samples containing two coplanar fissures in the process of deformation failure," Engineering Fracture Mechanics, vol. 78, no. 17, pp. 3059-3081, 2011. 

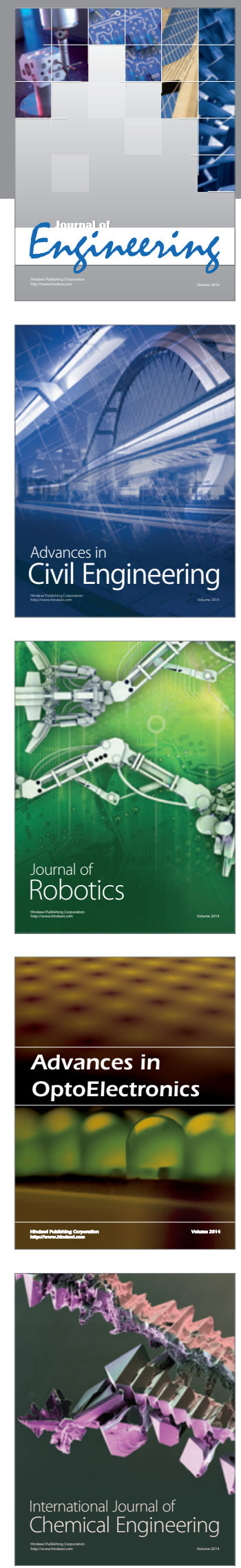

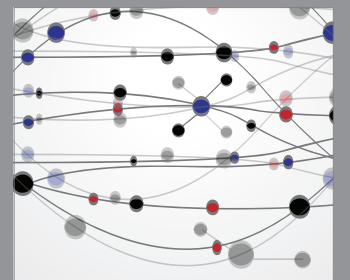

The Scientific World Journal
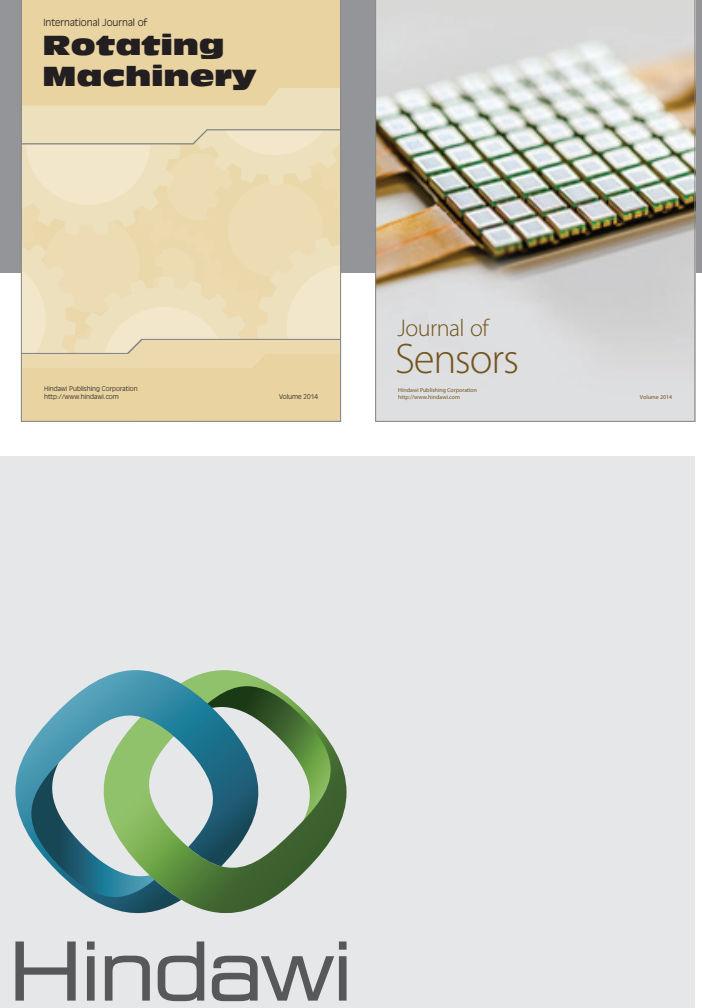

Submit your manuscripts at http://www.hindawi.com
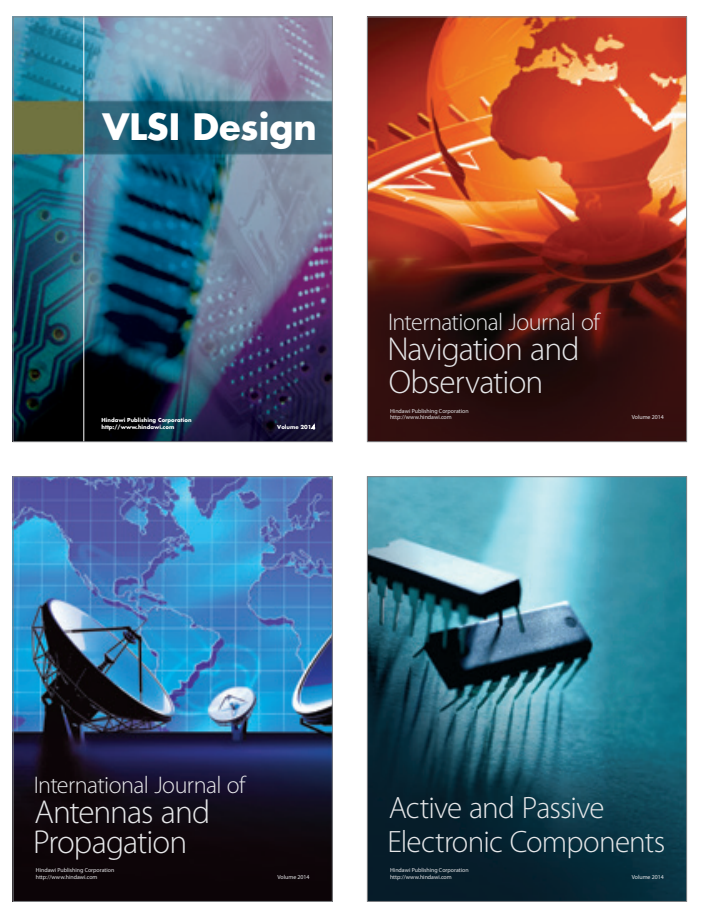
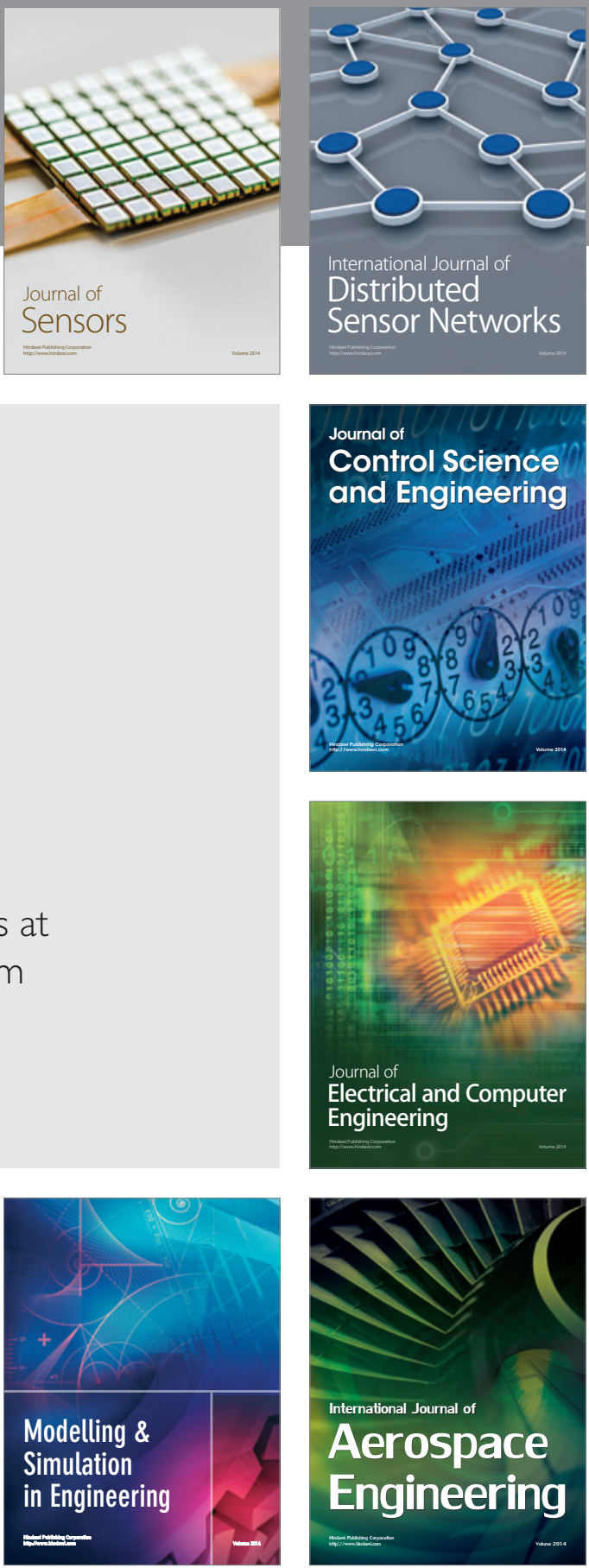

Journal of

Control Science

and Engineering
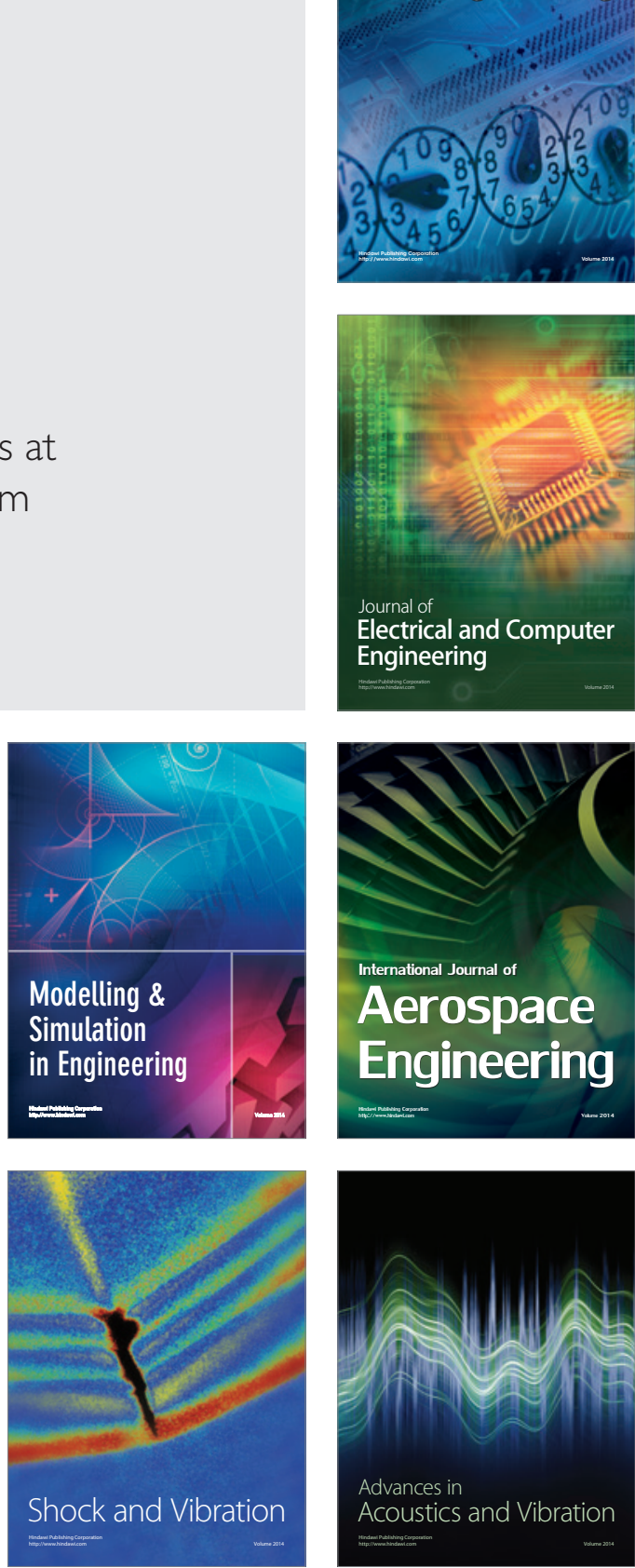